\title{
Does supplementation with selenium affect plasma lipids? Results of a randomized, controlled trial
}

\author{
Margaret Rayman ${ }^{1}$, Saverio Stranges ${ }^{2}$, Bruce Griffin ${ }^{1}$, Max Wong $^{1}$ and Eliseo Guallar ${ }^{3}$ \\ ${ }^{1}$ University of Surrey, Guildford GU2 7XH, UK, ${ }^{2}$ University of Warwick Medical School, Coventry CV4 7AL, UK and \\ ${ }^{3}$ Johns Hopkins University Bloomberg School of Public Health, Baltimore, MD 21205, USA
}

Evidence that selenium affects CHD risk is equivocal, despite a good biological rationale for a beneficial effect of optimal selenoprotein activity and concentration. However, concern has surfaced recently about possible associations of high selenium exposure with cardiometabolic risk. A number of sizeable cross-sectional analyses have shown an association between high selenium status in adults and elevated serum or plasma concentrations of total, LDL and non-HDL cholesterol ${ }^{(1-3)}$, but there is virtually no data from randomized clinical trials on the effect of selenium supplementation on plasma lipids.

The UK PRECISE Pilot study, in which 501 elderly volunteers were randomly assigned to a 6-month treatment with $100,200 \mathrm{or} 300 \mu \mathrm{g}$ selenium/d as high-selenium yeast or placebo yeast, provided a unique opportunity to investigate the impact of selenium supplementation on plasma lipids. The total and HDL cholesterol were measured on stored plasma samples by routine colorimetric assays on an ILab 650 auto-analyser in 454 participants at baseline and 394 participants at 6 months. Plasma selenium was measured by hydride-generation inductively coupled-plasma mass spectrometry. Data were analysed using mixed models for longitudinal data, adjusted for the treatment centre.

Mean (SD) plasma selenium was 88.7 (19.3) ng/g at baseline, but rose significantly in the 100, 200 and $300 \mu \mathrm{g} / \mathrm{d}$ treatment groups at 6 months (see Table 1). Supplementation with selenium at 100 and $200 \mu \mathrm{g} / \mathrm{d}$ lowered total serum cholesterol and non-HDL cholesterol. The $300 \mu \mathrm{g} / \mathrm{d}$ dose had no significant effect on total or non-HDL cholesterol, but raised HDL cholesterol significantly.

Table 1. Effect of supplementation on mean plasma selenium and mean lipid concentrations after 6 months

\begin{tabular}{|c|c|c|c|c|c|c|c|}
\hline \multirow{2}{*}{$\begin{array}{l}\text { Selenium } \\
\text { dose }(\mu \mathrm{g} / \mathrm{d})\end{array}$} & \multirow{2}{*}{$\begin{array}{c}\text { Change (SD) in plasma } \\
\mathrm{Se}(\mathrm{ng} / \mathrm{g})\end{array}$} & \multicolumn{2}{|c|}{ Total cholesterol $(\mathrm{mmol} / \mathrm{l})$} & \multicolumn{2}{|c|}{ HDL cholesterol $(\mathrm{mmol} / \mathrm{l})$} & \multicolumn{2}{|c|}{ Non-HDL cholesterol $(\mathrm{mmol} / \mathrm{l})$} \\
\hline & & Change $(95 \% \mathrm{CI})$ & $P$-value & Change $(95 \% \mathrm{CI})$ & $P$-value & Change $(95 \% \mathrm{CI})$ & $\overline{P \text {-value }}$ \\
\hline 0 (placebo) & $0.05(18.7)$ & Reference & & Reference & & Reference & \\
\hline 100 & $57.7(26.0)$ & $-0.23(-0.42,-0.03)$ & 0.02 & $-0.02(-0.08,0.03)$ & 0.46 & $-0.20(-0.37,-0.04)$ & 0.017 \\
\hline 200 & $100.2(37.6)$ & $-0.25(-0.44,-0.07)$ & 0.008 & $0.01(-0.04,0.06)$ & 0.70 & $-0.27(-0.42,-0.10)$ & 0.001 \\
\hline 300 & $135.0(50.9)$ & $-0.07(-0.26,0.12)$ & 0.46 & $0.06(0.00,0.11)$ & 0.045 & $-0.13(-0.30,0.03)$ & 0.12 \\
\hline$P$-value* & $<0.001$ & & 0.02 & & 0.037 & & 0.01 \\
\hline
\end{tabular}

*Overall $P$-value for comparing the three treatment groups $v$. placebo.

In view of the potential public-health implications of hyperlipidaemia and the widespread use of selenium-containing supplements, the results are reassuring. However, because of the relatively low baseline Se status of the population, the short duration of the intervention and the limited range of the age group involved (60-74 years), additional trials are needed to establish whether these results are more widely applicable. The full range of cardio-metabolic effects of selenium and its potential role in the prevention of CVD need to be further explored.

1. Bleys J, Navas-Acien A, Stranges S et al. (2008) Serum selenium and serum lipids in US adults. Am J Clin Nutr 88, $416-423$.

2. Laclaustra M, Stranges S, Navas-Acien A et al. (2010) Serum selenium and serum lipids in US adults: National Health and Nutrition Examination Survey (NHANES) 2003-2004. Atherosclerosis 210, 643-648.

3. Stranges S, Laclaustra M, Ji C, Cappuccio FP et al. (2010) Higher selenium status is associated with adverse blood lipid profile in British adults. J Nutr 140, 81-87 (Epublication ahead of print 11 November 2009). 